\title{
A Diurnal Rhythm of Stimulatory Input to the Hypothalamo-Pituitary-Adrenal System as Revealed by Timed Intrahypothalamic Administration of the Vasopressin $V_{1}$ Antagonist
}

\author{
Andries Kalsbeek, Joop J. van Heerikhuize, Joke Wortel, and Ruud M. Buijs \\ Netherlands Institute for Brain Research, 1105 AZ Amsterdam, The Netherlands
}

The mammalian suprachiasmatic nuclei (SCN) contain an endogenous pacemaker that generates daily rhythms in behavior and secretion of hormones. We hypothesized that the SCN imposes its circadian rhythm on the rest of the brain via a rhythmic release of its transmitters in its target areas. Previously, we demonstrated a pronounced inhibitory effect of vasopressin (VP), released from SCN terminals in the dorsomedial hypothalamus, on the release of the adrenal hormone corticosterone. In the present study, microdialysis-mediated intracerebral administration of the VP $V_{1}$-receptor antagonist was used to pursue the study of the mechanisms underlying the circadian control of basal corticosterone release. Using timed administrations of the VP antagonist divided equally over the day/night cycle, we were able to uncover the existence of an additional stimulatory input from the SCN to the hypothalamopituitary-adrenal (HPA) axis. Peak activity of this stimulatory SCN input takes place during the second half of the light period, after the daily peak of VP secretion, with a delay of 4-6 hr. In all likelihood, the inhibitory and stimulatory circadian input via separate mechanisms affects corticosterone release. Together, these two opposing circadian control mechanisms of the HPA axis enable a precise timing of the circadian peak in corticosterone release.

Key words: circadian rhythms; vasopressin; glucocorticoids; microdialysis; paraventricular/dorsomedial hypothalamus; suprachiasmatic nuclei
The prominent diurnal peak in circulating levels of adrenal steroids before the onset of the daily period of increased activity has been described in numerous species, including rats (Guillemin et al., 1959; McCarthy et al., 1960), monkeys (Perlow et al., 1981; Carnes et al., 1988), domestic animals (Lincoln et al., 1982; Klemcke et al., 1989; Lefcourt et al., 1993; Irvine and Alexander, 1994), and humans (Van Cauter, 1990; Linkowski et al., 1993). In diurnal species such as the human and the pig, plasma glucocorticoid levels are high in the early morning and then decline, reaching a nadir in the evening. In nocturnal animals, including the laboratory rat, an inverse pattern is observed with a nadir in the morning and a peak near the onset of darkness. The endogenous nature of this rhythm in adrenocortical activity appeared from the fact that it persisted in constant darkness with an almost 24 hr (i.e., circadian) rhythm (Takahashi et al., 1977; Perlow et al., 1981; Fischman et al., 1988). In rats, the major adrenal steroid that is secreted is corticosterone, and this secretion is directly stimulated by adrenocorticotropic hormone (ACTH) secretion from corticotrophs in the anterior pituitary gland. In its turn, ACTH is driven by the release of corticotrophin-releasing hormone $(\mathrm{CRH})$ in the portal system of the median eminence. The $\mathrm{CRH}$-containing cell bodies reside in the parvocellular part of the paraventricular nucleus of the hypothalamus (PVN).

The hypothalamo-pituitary-adrenal (HPA) axis is of critical importance for homeostasis, because it minimizes deviations from the homeostatic state and helps the return to equilibrium after stress-induced disturbances, so that harmful effects of overactivity

Received Jan. 31, 1996; revised June 10, 1996; accepted June 13, 1996.

We thank Wilma Verweij for correcting the English and Henk Stoffels for preparing the illustrations.

Correspondence should be addressed to Andries Kalsbeek, Netherlands Institute for Brain Research, Meibergdreef 33, 1105 AZ Amsterdam, The Netherlands. Copyright (C) 1996 Society for Neuroscience $0270-6474 / 96 / 165555-11 \$ 05.00 / 0$ are avoided (Munck et al., 1984). Glucocorticoids also play an important, although not fully defined, role in several metabolic and behavioral systems, having an impact on body weight and food intake control. The diurnal peak in corticosterone release at the end of a period of inactivity and fasting may serve to prepare the animal for the coming period of increased activity by mobilizing stored energy (Devenport et al., 1993; Hamelink et al., 1994; Challet et al., 1995). In addition, the diurnal corticosterone rise stimulates carbohydrate and fat intake (Tempel and Leibowitz, 1994), and it may initiate food-searching behavior (Hamelink et al., 1994; Challet et al., 1995).

The main force driving the endogenous circadian rhythm of basal HPA activity is the suprachiasmatic nucleus (SCN) in the anterior hypothalamus (Moore and Eichler, 1972; Abe et al., 1979; Szafarczyk et al., 1979; Cascio et al., 1987). In a number of previous studies, we provided evidence for an important inhibitory role of SCN-derived vasopressin (VP) with respect to the basal release of corticosterone. However, it became clear that an additional (stimulatory) input was needed to explain the complete daily profile of circulating plasma corticosterone levels (Kalsbeek et al., 1996). To uncover the diurnal pattern of this stimulatory input to the HPA axis, we blocked the inhibitory input of the SCN by infusions of the $\mathrm{VP} \mathrm{V}_{1}$-antagonist at five different time points of the day/night cycle. Because changes in plasma ACTH were assumed to much more closely reflect changes in the central regulation of the HPA axis, both plasma corticosterone and ACTH levels were measured.

\section{MATERIALS AND METHODS}

Animals. Male Wistar rats were obtained from a commercial supplier (TNO, Zeist, The Netherlands) and housed in macrolon cages with four animals per cage in a room with a 12:12 hr light/dark schedule (lights on at 07:00). One week before the start of experiments, animals were moved to individual cages $\left(38 \times 26 \times 16 \mathrm{~cm}^{3}\right)$. Food and water were available ad 


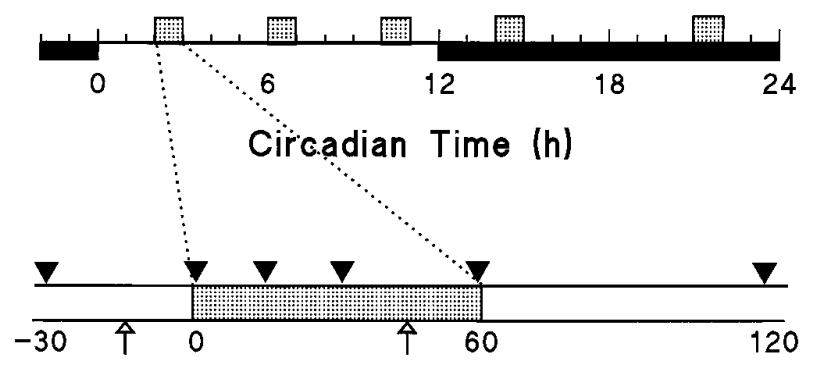

VP-antagonist

Blood samples

$\uparrow$ Syringe change

Figure 1. Schematic outline of the experimental design used in the present study. Dark period is indicated by the solid horizontal bar. The stippled boxes indicate the $1 \mathrm{hr}$ infusion periods of VP antagonist. Triangles indicate time points of blood sampling.

libitum. Animals weighed between 300 and $350 \mathrm{gm}$ at the time of the experiments.

Microdialysis probes. Dialysis probes were constructed according to procedures described previously in detail and routinely used in this laboratory (Kalsbeek et al., 1995, 1996). Thin platinum wire $(\phi 0.05 \mathrm{~mm})$ was inserted into a piece of microdialysis tubing (molecular weight cutoff, $6000 \mathrm{kDa}$ ), bent, and each end was inserted into one of two pieces of 25 gauge hypodermic tubing that had been soldered together. The dialysis tubing was then secured with epoxy. The U-shaped tip of the dialysis probe was $1.5 \mathrm{~mm}$ long, $0.7 \mathrm{~mm}$ wide, and $0.2 \mathrm{~mm}$ thick.

Surgical procedures. Experimental animals destined to undergo infusion and blood sampling studies were fitted with a unilateral microdialysis probe and a silicone catheter in the right atrium when their body weight was $>300 \mathrm{gm}$. The microdialysis probe was stereotaxically implanted lateral to the dorsomedial nucleus of the hypothalamus (DMH) (coordinates with flat skull: $2.8 \mathrm{~mm}$ caudal to bregma; $1.6 \mathrm{~mm}$ lateral to the midline; $8.0 \mathrm{~mm}$ below the brain surface; $10^{\circ}$ angled to the sagittal plane). The loop of the probe was positioned in the rostrocaudal direction along the DMH. Jugular venectomy was performed according to the method of Steffens (Steffens, 1969). We used dental cement to secure the probe and atrial outlet to two stainless steel screws inserted in the skull.

General protocol. After implantation of the microdialysis probe and the jugular catheter, the animals were allowed at least 1 week of postoperative recovery before the experiments began. During this period, the animals became accustomed to the experimental conditions in Plexiglas cages, designed to allow blood sampling and long-term infusions under unrestrained conditions. All experiments were performed in the animals' own home cage. The input port of the dialysis probe was connected to a remote syringe via a fluid swivel (Instech 375/22) interconnected with polyethylene tubings. Tubings to and from the probe were threaded through a stainless steel support spring that was attached to the dental cement. The entire assembly was suspended from a counter-balanced beam and did not influence the animals' posture or motion. The syringe contained Ringer's fluid with or without the vasopressin $V_{1}$ antagonist (50 $\mathrm{ng} / \mu \mathrm{l})$. Ringer's perfusion ( $3 \mu \mathrm{l} / \mathrm{min}$ ) was started $4 \mathrm{hr}$ before the $1 \mathrm{hr} \mathrm{V}_{1}$ antagonist infusion period and lasted for 3 more hr after the change back to Ringer's (Fig. 1). Dialysates were changed by connecting the polyethylene tubing from the appropriate syringe to the fluid swivel. The dead space between the fluid swivel and dialysis membrane was $45 \mu \mathrm{l}$. Therefore, dialysate containing the $\mathrm{V}_{1}$ antagonist reached the membrane 15 min after the change of syringes. One hour infusion periods of $\mathrm{V}_{1}$ antagonist were initiated at circadian times 2, 6, 10, 14, and 21 (CT; CT12 being defined as the onset of darkness). Blood samples $(0.3 \mathrm{ml})$ were taken 30 and $1 \mathrm{~min}$ before the start of the $\mathrm{V}_{1}$ antagonist infusion, and 15, 30, 60, and 120 min after onset of this infusion (Fig. 1). To prevent any stimulation of ACTH and corticosterone release because of blood replacement, the total blood volume sampled was returned as saline only after the final blood sample was taken. Previous reports have shown that this amount of blood can be removed with no risk of stimulating the HPA axis (Carnes et al., 1990). After the operation, a 7 d recovery period was included to allow complete reinstatement of circadian rhythms in activity, body temperature, and plasma corticosterone (Drijfhout et al., 1995). Our previous studies have shown that despite the prolonged implantation of the dialysis cannula, VP antagonist can still be administered effectively to the brain (recovery between 0.5 and $0.1 \%$ ), provided that the dialysis probe is not perfused during the recovery period (Kalsbeek et al., 1996). Because the efficacy of drug delivery will decrease after the first use of the dialysis probe (Kalsbeek and Buijs, 1996), only VP antagonist data obtained during a first infusion were used. Most animals took part in two experiments, namely, no dialysis or dialysis of Ringer's and a VP antagonist infusion, on subsequent days. To control for blood loss and other possible effects of experimentation, control data were obtained by either no perfusion on day 1 followed by VP antagonist on day 2, or VP antagonist administration on day 1 followed by Ringer's perfusion on day 2 .

Two additional control experiments were performed. In one group of animals $(n=6)$, microdialysis probes were implanted in the ventromedial hypothalamus (VMH) (coordinates with flat skull: $3.1 \mathrm{~mm}$ caudal to bregma; $3.5 \mathrm{~mm}$ lateral to the midline; $9.2 \mathrm{~mm}$ below the brain surface; with a $10^{\circ}$ angle from the sagittal plane) to get an impression about the extent of VP antagonist distribution away from the site of dialysis. Animals were treated in the same way as CT6 animals. Another group of animals $(n=7)$ was subjected to an arousing stimulus to compare stress-induced and $\mathrm{V}_{1}$ antagonist-induced activation of the HPA axis. One week after having been engaged in the dialysis experiments, animals were put in a new cage without sawdust bedding for $1 \mathrm{hr}$, starting at CT6. The blood sampling protocol was similar to that used for the dialysis experiments.

Histology. When the experimental protocol was completed, the animals were anesthetized with pentobarbital (Nembutal; $60 \mathrm{mg} / \mathrm{kg}$, i.v.), and their brains were removed after decapitation. Brains were subsequently blocked, frozen, sectioned $(40 \mu \mathrm{m})$ through the region of the PVN and $\mathrm{DMH}$, and stained with cresyl violet. Examples of the probe track have been provided previously (Kalsbeek et al., 1996).

Chemicals. Plasma samples were assayed for corticosterone by radioimmunoassay (RIA; ICN Biomedicals, Costa Mesa, CA). From the samples, $10 \mu \mathrm{l}$ was taken and diluted in $4 \mathrm{ml}$ of assay buffer. The interand intra-assay coefficients of variance (CV) were 7 and $4 \%$, respectively, with a detection limit of $1 \mathrm{ng} / \mathrm{ml}$.

ACTH immunoreactivity was measured in duplicates of $25 \mu \mathrm{l}$ unextracted plasma using a commercially available kit from ICN (ICN Biomedicals). The $\mathrm{ED}_{50}$ of the assay was $56.7 \pm 2.5 \mathrm{pg} / \mathrm{ml}(n=16)$, with a detection limit of $10 \mathrm{pg} / \mathrm{ml}$. The intra-assay CV ranged from 4.1 to $6.0 \%$, and the interassay $\mathrm{CV}$ was between 4.0 and $10.7 \%$. If all samples from one CT could not be run in one assay, the Ringer's and $V_{1}$ antagonisttreated groups were equally divided among assays.

The vasopressin $\mathrm{V}_{1}$ antagonist used was $\mathrm{d}\left(\mathrm{CH}_{2}\right)_{5} \operatorname{Tyr}(\mathrm{Me}) \mathrm{AVP}$ (Manning and Sawyer, 1984; Manning et al., 1993).

Statistics. All quantitative results are expressed as mean \pm SEM. The significance of infusion-induced variation in plasma corticosterone and ACTH values (time dependency) was assessed using a one-way ANOVA with repeated measures (Tables 1 and 3). If significant, ANOVA was followed by a Student's $t$ test (paired) to establish the significance of the difference between "time -1 " and "time 30" values (Fig. 5). Multivariate analysis of variance (MANOVA) with factors Drug and Sampling (repeated measures) was used to determine whether the effects of Ringer's and VP antagonist on plasma corticosterone and ACTH concentrations differed significantly. Post hoc analysis was performed using the StudentNewman-Keuls test (SNK). The results were considered significant if the probability of error was $<5 \%$.

\section{RESULTS}

No differences were found between plasma corticosterone curves of animals having experienced a Ringer's dialysis and nondialyzed animals. Data of these two groups were therefore combined and treated as one control group (i.e., Ringer's group). The five plasma corticosterone profiles, collected during the control experiments at different times of the light/dark cycle, together revealed a clear diurnal release (Fig. 2). Notwithstanding the intracerebral infusion via the microdialysis probe, basal levels of corticosterone were very similar to the previously established rhythm in intact control animals without brain cannulae (Kalsbeek et al., 1996). The lowest levels of plasma corticosterone $(10-25 \mathrm{ng} / \mathrm{ml})$ were observed in the early light period during the CT2 experiments. In the course of the light period, circulating levels of plasma corticosterone increased, with interme- 


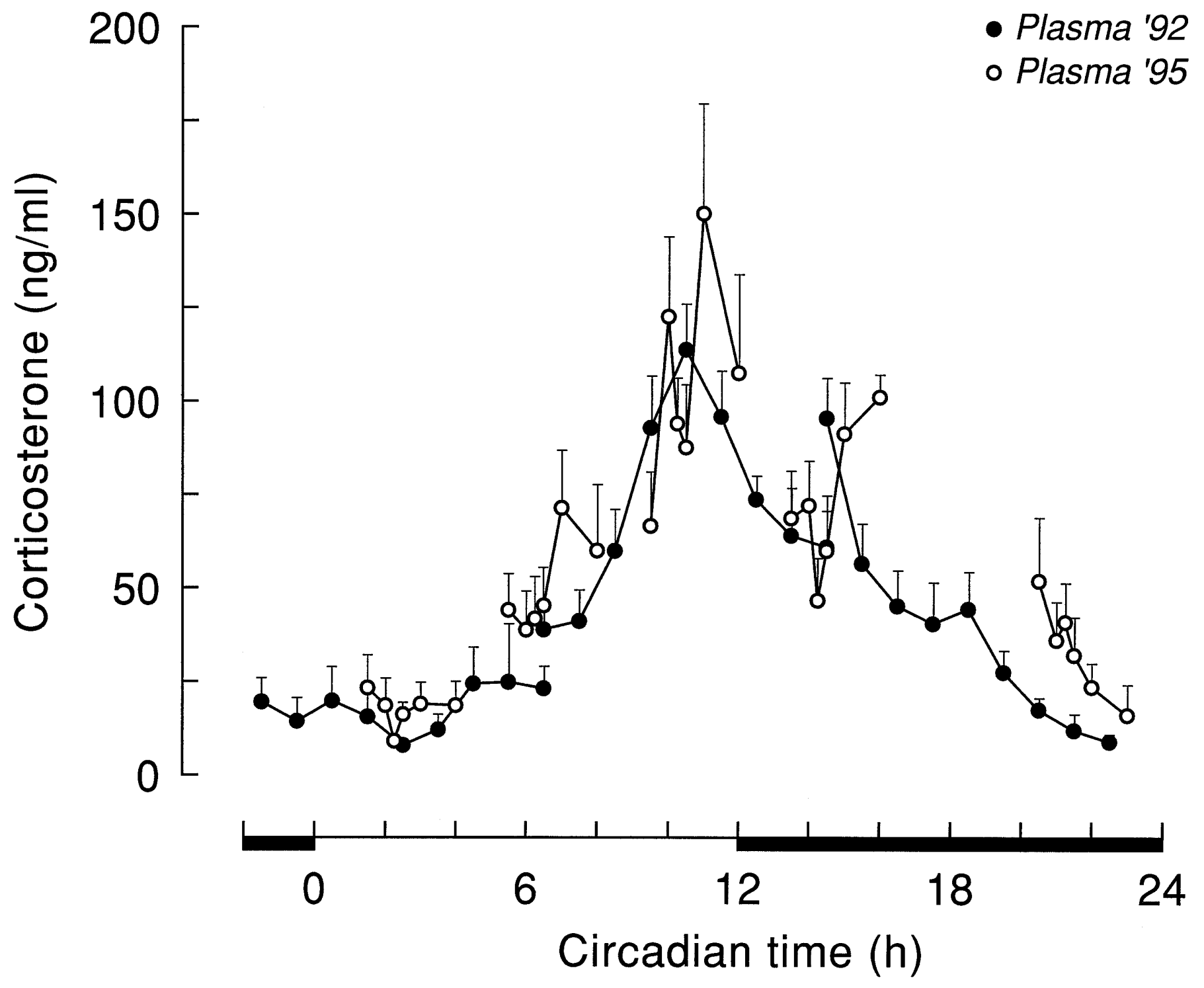

Figure 2. Plasma corticosterone values (mean \pm SEM) during Ringer's dialysis at different CT times (i.e., Plasma '95, $\bigcirc$ ) compared with a previously established plasma corticosterone curve (i.e., Plasma '92, $\mathbf{0} ; n=10$ ) in control animals without an intracerebral probe. The plasma ' 92 data are redrawn from Kalsbeek et al. (1996).

diate values at the CT6 infusion period, to reach peak levels (147 \pm $20 \mathrm{ng} / \mathrm{ml}$ ) shortly before onset of darkness, during the CT10 infusion period. In the course of the dark period, circulating corticosterone levels leveled off again, to reach minimal values before onset of the light period by the end of the CT21 infusion period. ANOVA did not yield a significant effect of Sampling in any of the control groups ( $p>0.05$ ), although during the CT10 infusion, the Sampling effect approached significance ( $p=0.061$; Table 1$)$. However, the pronounced diurnal fluctuation of circulating corticosterone levels was clearly reflected in the significant differences between basal corticosterone values at the onset of the $1 \mathrm{hr}$ infusion periods (Table 2) and between the different corticosterone profiles collected during the subsequent $\mathrm{CT}$ times $\left(F_{(43,4)}=21.24 ; p<0.001\right)$. Post hoc analysis (SNK) revealed that all CT10 sampling points differed from the corresponding sampling points at CT2, CT6, and CT21.

The disinhibiting effect of a $1 \mathrm{hr}$ hypothalamic infusion of the vasopressin $\mathrm{V}_{1}$ antagonist on corticosterone and ACTH release is shown in Figures 3 and 4 and Tables 1 and 3. ANOVA on the

\begin{tabular}{|c|c|c|c|c|c|c|}
\hline & CT2 & CT6 & CT10 & CT14 & CT21 & VMH \\
\hline \multicolumn{7}{|c|}{ One-way ANOVA } \\
\hline \multirow[t]{2}{*}{ Ringer's } & 0.683 & 0.331 & 0.061 & 0.167 & 0.189 & 0.144 \\
\hline & 11 & 11 & 11 & 7 & 8 & 6 \\
\hline \multirow[t]{2}{*}{ Anta } & 0.000 & 0.000 & 0.000 & 0.025 & 0.146 & 0.394 \\
\hline & 11 & 10 & 13 & 6 & 8 & 6 \\
\hline \multicolumn{7}{|c|}{ Two-way ANOVA } \\
\hline Drug & 0.030 & 0.001 & 0.088 & 0.410 & 0.003 & 0.748 \\
\hline Sampling & 0.000 & 0.000 & 0.000 & 0.650 & 0.114 & 0.451 \\
\hline $\mathrm{D} \times \mathrm{S}$ & 0.000 & 0.000 & 0.001 & 0.002 & 0.186 & 0.153 \\
\hline
\end{tabular}

One-way ANOVA shows the $p$ values for the Sampling effects of either Ringer's or $\mathrm{V}_{1}$ antagonist (Anta) application on plasma corticosterone levels at the different CT. Two-way ANOVA indicates the significance of differences between Ringer's and VP antagonist administration (Fig. 3). Number of animals is indicated in italics. 


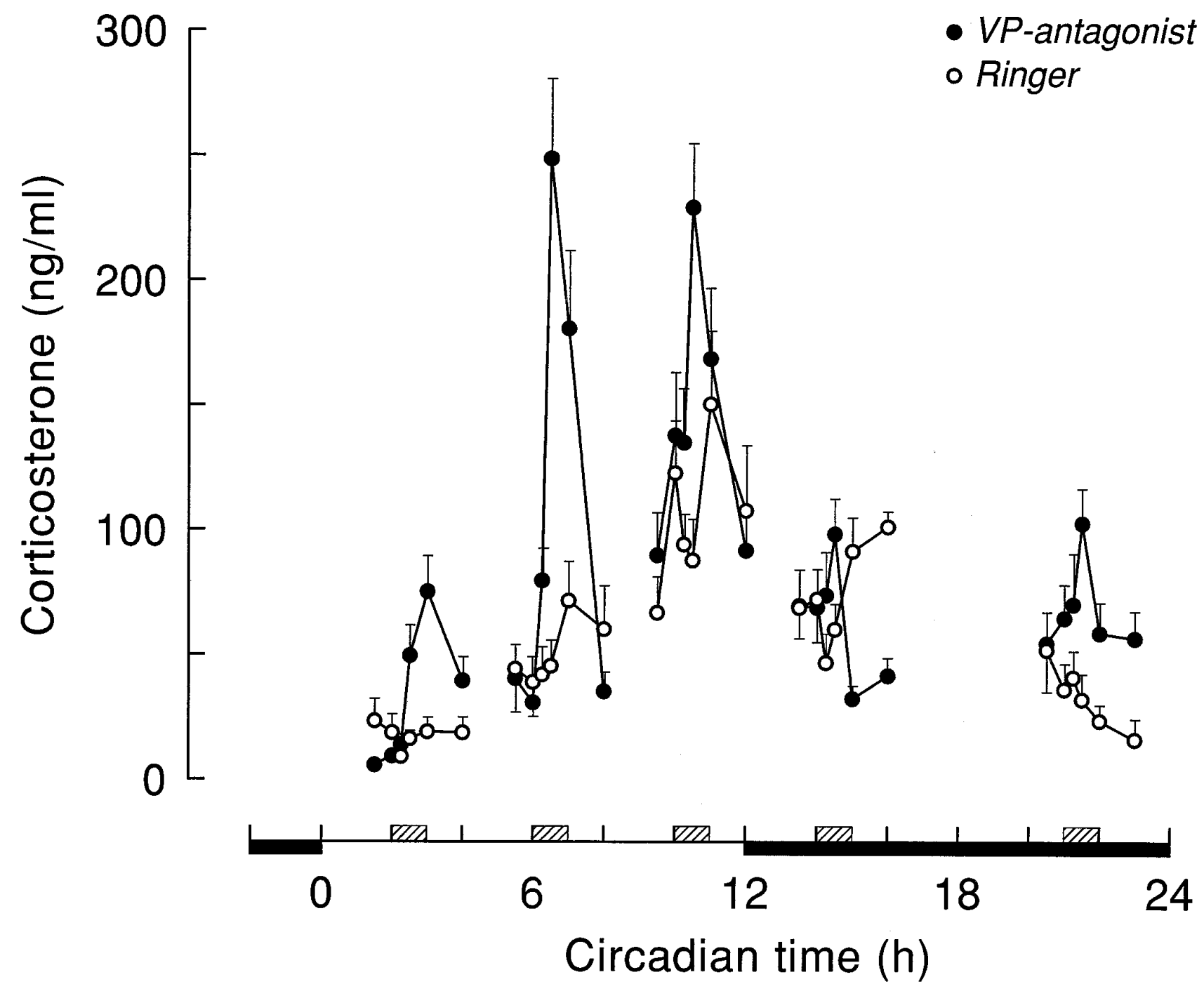

Figure 3. Plasma corticosterone values (mean \pm SEM) during Ringer's $(\bigcirc)$ or VP antagonist $(\bullet)$ administration in the PVN/DMH area. Hatched boxes indicate the timing of the $1 \mathrm{hr}$ period of VP antagonist administration.

separate infusion periods indicated pronounced Sampling effects of the VP antagonist infusions on plasma corticosterone at CT2, CT6, and CT10 $(p<0.001)$ (Table 1). On the other hand, effects at the other time points were less pronounced (CT14) or nonsignificant (CT21). Differences between the effect of Ringer's and administration of $\mathrm{V}_{1}$ antagonist were most clearly expressed at CT6 and CT2, with MANOVA showing highly significant effects $(p<0.005)$ of Drug, Sampling, and Drug $\times$ Sampling. Although the Drug effect just escaped significance at CT10 $(p=0.088)$, there were clear effects of both Sampling and Drug $\times$ Sampling $(p<0.001)$. At CT21, there was also a significant Drug effect $(p=0.001)$, but no Sampling or Interaction effect $(p>0.05)$. At CT14, MANOVA revealed only a significant Interaction effect $(p=0.002)$, but no significant effects of Drug or Sampling $(p>$ $0.1)$. Taking into account the diurnal changes in basal corticosterone secretion, Figure $5 A$ displays the above results in a different setting. Control and VP antagonist-induced changes in plasma corticosterone levels are now displayed as the difference between the $t=-1$ and $t=30 \mathrm{~min}$ time points, instead of the absolute plasma corticosterone values. This representation makes it even clearer that only during the daytime infusions of the $V_{1}$ antagonist a pronounced rise in plasma corticosterone was found.
In the present study, the unilateral application of VP antagonist at CT6 by microdialysis was equally effective in eliciting a rise of plasma corticosterone as our earlier bilateral microinjections (Kalsbeek et al., 1992). On the other hand, more recently we were not able to block completely the circadian rise in plasma corticosterone with a unilateral application of VP (Kalsbeek et al., 1996). Therefore, a partial blockade of the inhibitory input to the HPA axis by unilateral blockade of the VP receptors is sufficient to reveal the excitatory input to the HPA axis, but, for a complete inhibition of the excitatory activity in the HPA-system, it seems that a bilateral blockade of all stimulatory inputs is necessary.

The effect of a $1 \mathrm{hr}$ administration of VP antagonist into the $\mathrm{VMH}$ on plasma corticosterone values is illustrated in Figure 6. ANOVA on the VMH data separately revealed no significant effect of either the Ringer's or $\mathrm{V}_{1}$ antagonist administration (effects of Drug, Sampling, and Interaction all $p>0.1$ ). Comparing the administration of VP antagonist into the VMH with that into the PVN/DMH area at the same CT time showed significantly higher plasma corticosterone values $30 \mathrm{~min}$ after the antagonist entered the PVN/DMH area. However, at $t=120$, plasma corticosterone values in the $\mathrm{VMH}$ group were significantly elevated compared with PVM/DMH administration (SNK, $p<0.05$ ). 


\begin{tabular}{|c|c|c|c|c|c|c|c|}
\hline & $\mathrm{CT} 2$ & CT6 & CT10 & CT14 & CT21 & $\mathrm{VMH}$ & Stress \\
\hline \multicolumn{8}{|c|}{ ACTH $(\mathrm{pg} / \mathrm{ml})$} \\
\hline & 11 & 11 & 10 & 7 & 8 & - & 7 \\
\hline \multirow[t]{2}{*}{ Anta } & $38.6 \pm 4.0$ & $35.9 \pm 1.8$ & $33.5 \pm 2.4$ & $41.1 \pm 4.1$ & $39.4 \pm 4.2$ & - & - \\
\hline & 11 & 10 & 13 & 6 & 8 & - & - \\
\hline & 11 & 11 & 10 & 7 & 8 & 6 & 7 \\
\hline \multirow[t]{2}{*}{ Anta } & $9.3 \pm 2.4$ & $30.7 \pm 5.8$ & $137.7 \pm 25.5$ & $68.8 \pm 14.1$ & $64.6 \pm 13.4$ & $45.3 \pm 17.7$ & - \\
\hline & 11 & 10 & 13 & 6 & 8 & 6 & - \\
\hline
\end{tabular}

Number of animals is indicated in italics.

Basal ACTH release during control experiments at different time points of the light/dark cycle revealed no clear diurnal variation, and mean values varied between 35 and $45 \mathrm{pg} / \mathrm{ml}$ (Table 2). In accordance with this outcome, no significant differences between ACTH plasma profiles during the five diurnal infusion periods were observed $\left(F_{(4,43)}=0.32 ; p>0.5\right)$. In addition, none of the three Ringer's infusions administered during the light period yielded significant Sampling effects with ANOVA (Table 3). However, during the CT21 Ringer's infusion, a significant decline of circulating plasma ACTH levels occurred.

Effects of Ringer's and VP antagonist application on plasma ACTH levels are displayed in Figure 4. All three daytime infusions of the $\mathrm{V}_{1}$ antagonist evoked significant time-dependent effects $(p<0.001$; Table 3$)$. The increased release at CT21 did not reach the level of significance. The ACTH excursions were small, which is evidenced by the lack of a significant main effect of Drug at any time (Table 3). However, the significant Interaction effects during the daytime infusion periods indicate the different reaction of plasma ACTH to either a Ringer's or a VP antagonist infusion (Table 3). The mean values of plasma ACTH $30 \mathrm{~min}$ after onset of a $V_{1}$ antagonist application also differed most significantly from preinfusion or Ringer's infusion values during daytime experiments (Fig. $5 B$ ).

The arousing stimulus of a new cage clearly activated the HPA axis, as evidenced by the profound increases in both plasma ACTH and corticosterone (Fig. 7). Stress-induced corticosterone excursions, however, were significantly smaller and shorter-lasting than those induced by PVN/DMH administration of the $\mathrm{V}_{1}$ antagonist (Fig. $\left.7 A ; F_{(2,25)}=7.75 ; p=0.002\right)$. On the other hand, plasma ACTH increases were more pronounced during exposure to the new cage compared with the VP antagonist, especially during the first $15 \mathrm{~min}$ (Fig. $7 B ; F_{(2,25)}=6.65 ; p=0.005$ ). Unfortunately, basal ACTH values significantly differed between the dialysis and the experiments with a new cage (Table 2), most likely because of interassay variation. When the data were expressed as a percent increase of basal $t=-1$ values, however, the significant differences remained $\left(F_{(2,25)}=4.76 ; p=0.018\right)$. The relation between plasma ACTH and the concurrent plasma corticosterone values is displayed in Figure 8. Also, this scatter plot illustrates the different regulation of HPA activity during either novelty stress or infusion of a VP antagonist.

\section{DISCUSSION}

The present study, using microdialysis-mediated administration of VP antagonist, demonstrated that blockade of VP receptors in the dorsomedial hypothalamus evokes a disinhibition of the HPA axis. However, this stimulating effect of the VP antagonist application depended heavily on the time of day. Previously, we showed a strong inhibitory effect of exogenous VP on elevated corticosterone levels in SCN-lesioned animals (Kalsbeek et al., 1992). More recently, we also described an inhibitory effect of endogenous VP on corticosterone release in intact animals during the middle of the light period (Kalsbeek et al., 1996). In addition, we found that application of exogenous VP to the DMH at the end of the light period prevents the circadian rise in plasma corticosterone (Kalsbeek et al., 1996). Taken together, these results illustrated that a fluctuating inhibitory signal emanating from the SCN via the release of VP is crucially involved in the shaping of the corticosterone rhythm. Indeed, the high release of VP from SCN terminals during the light period (Reppert et al., 1981; Kalsbeek et al., 1995) coincides precisely with the low levels of circulating corticosterone at this time of the day.

However, it is also clear that the circadian release pattern of VP alone cannot completely explain the daily corticosterone rhythm. Most importantly, the relation between VP release and basal corticosterone shows a mismatch during the second half of the dark phase; i.e., despite the absence of the inhibitory VP signal, basal corticosterone release is low. Also, blockade of the vasopressinergic inhibition produces corticosterone levels that greatly exceed those of the basal diurnal peak. Finally, the fact that in the absence of the inhibitory SCN signal (i.e., in SCN-lesioned animals) plasma corticosterone levels are not continuously at peak

\begin{tabular}{|c|c|c|c|c|c|}
\hline & $\mathrm{CT} 2$ & СТ6 & CT10 & CT14 & CT21 \\
\hline \multicolumn{6}{|c|}{ One-way ANOVA } \\
\hline \multirow[t]{2}{*}{ Ringer's } & 0.814 & 0.578 & 0.620 & 0.120 & 0.011 \\
\hline & 11 & 11 & 11 & 7 & 8 \\
\hline \multirow[t]{2}{*}{ Anta } & 0.000 & 0.000 & 0.000 & 0.545 & 0.111 \\
\hline & 11 & 10 & 13 & 6 & 8 \\
\hline \multicolumn{6}{|c|}{ Two-way ANOVA } \\
\hline Drug & 0.661 & 0.286 & 0.937 & 0.725 & 0.660 \\
\hline Sampling & 0.004 & 0.001 & 0.103 & 0.070 & 0.009 \\
\hline $\mathrm{D} \times \mathrm{S}$ & 0.042 & 0.000 & 0.005 & 0.831 & 0.203 \\
\hline
\end{tabular}

One-way ANOVA shows the $p$ values for the Sampling effects of either Ringer's or $\mathrm{V}_{1}$ antagonist (Anta) application on plasma ACTH values at the different CT. Two-way ANOVA indicates the significance of differences between absolute plasma ACTH values on Ringer's and VP antagonist administration (Fig. 4). Number of animals is indicated in italics. 


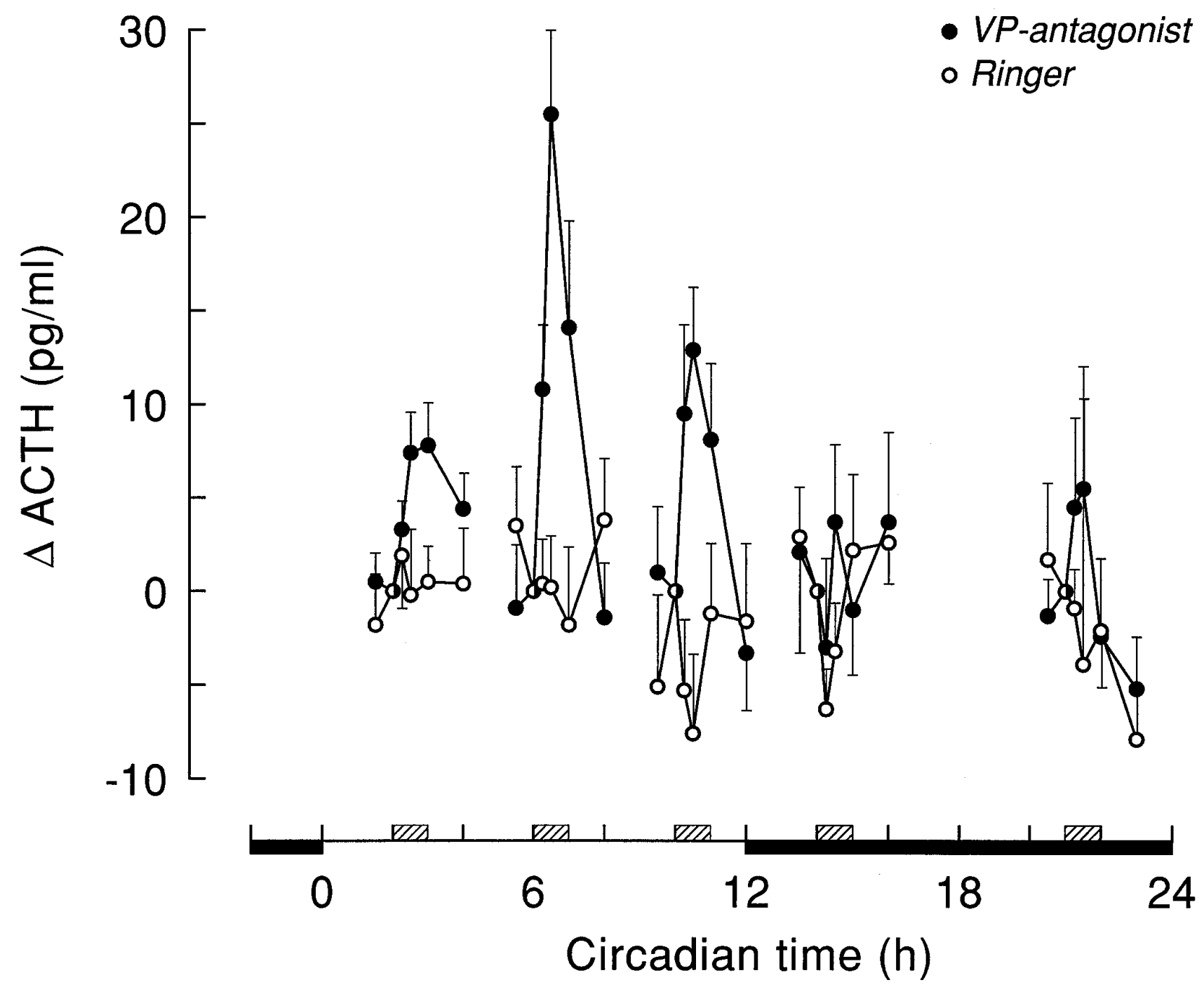

Figure 4. Plasma ACTH responses (mean \pm SEM) during Ringer's $(\bigcirc)$ and VP antagonist $(\bullet)$ administration in the PVN/DMH area. ACTH values are expressed as the difference compared with $t=-1$ (i.e., just before VP antagonist enters the brain). For ACTH values at $t=-1$, see Table 2 . Hatched boxes indicate the timing of the $1 \mathrm{hr}$ period of VP antagonist administration.

concentrations indicates that SCN lesions remove another (stimulatory) input to the HPA system as well (Cascio et al., 1987; Kalsbeek et al., 1992). Indeed, the existence of an additional stimulatory factor involved in the circadian control of basal corticosterone release would explain the above-mentioned VP corticosterone mismatches. In fact, the existence of a facilitatory SCN input into the HPA axis was already proposed several times (Cascio et al., 1987; Dallman et al., 1992; Kalsbeek et al., 1992), but real evidence has been lacking until now. Blockade of the inhibitory VP input to the HPA axis at different times during the day/night cycle enabled us to reveal that this stimulatory input does indeed exist and has a circadian release pattern, too. The diurnal fluctuation of the stimulatory input is most clearly displayed by the VP antagonist-induced changes in corticosterone and ACTH release (Fig. 5). As is evident from Figure 5, the stimulatory input to the HPA axis is strongest during the second half of the daytime, i.e., CT6 and CT10, but its expression may already begin during the final hour of the dark period.

Together, the postulated rhythmic inhibitory and stimulatory inputs from the $\mathrm{SCN}$ in the presently proposed phase relationship
(Fig. 9) fully explain the well known rhythm in resting plasma corticosterone levels. In addition, they are consistent with the day/night rhythmicity of SCN neuronal activity, showing peak activity during (subjective) daytime (Inouye and Kawamura, 1979; Gillette and Reppert, 1987; Bos and Mirmiran, 1990). During the first half of the light period, there is a strong inhibition of corticosterone release attributable to the increased release of SCNderived VP, and hardly any stimulatory input, which results in the lowest basal levels. In the course of the light period, the stimulatory input from the SCN increases but is not yet apparent, attributable to the ongoing high release of endogenous VP. At the end of the light period, the decrease in VP release from SCN terminals then makes full expression of the stimulatory SCN input possible. The apparent relationship between both factors induces a profound circadian peak of corticosterone. The importance of the decline in VP secretion is evidenced by our previous experiment, which showed that infusion of exogenous VP at this time of the light/dark cycle (i.e., CT8-CT12) prevents the diurnal peak in corticosterone release (Kalsbeek et al., 1996). With the onset of darkness, both the inhibitory and stimulatory input from the SCN 

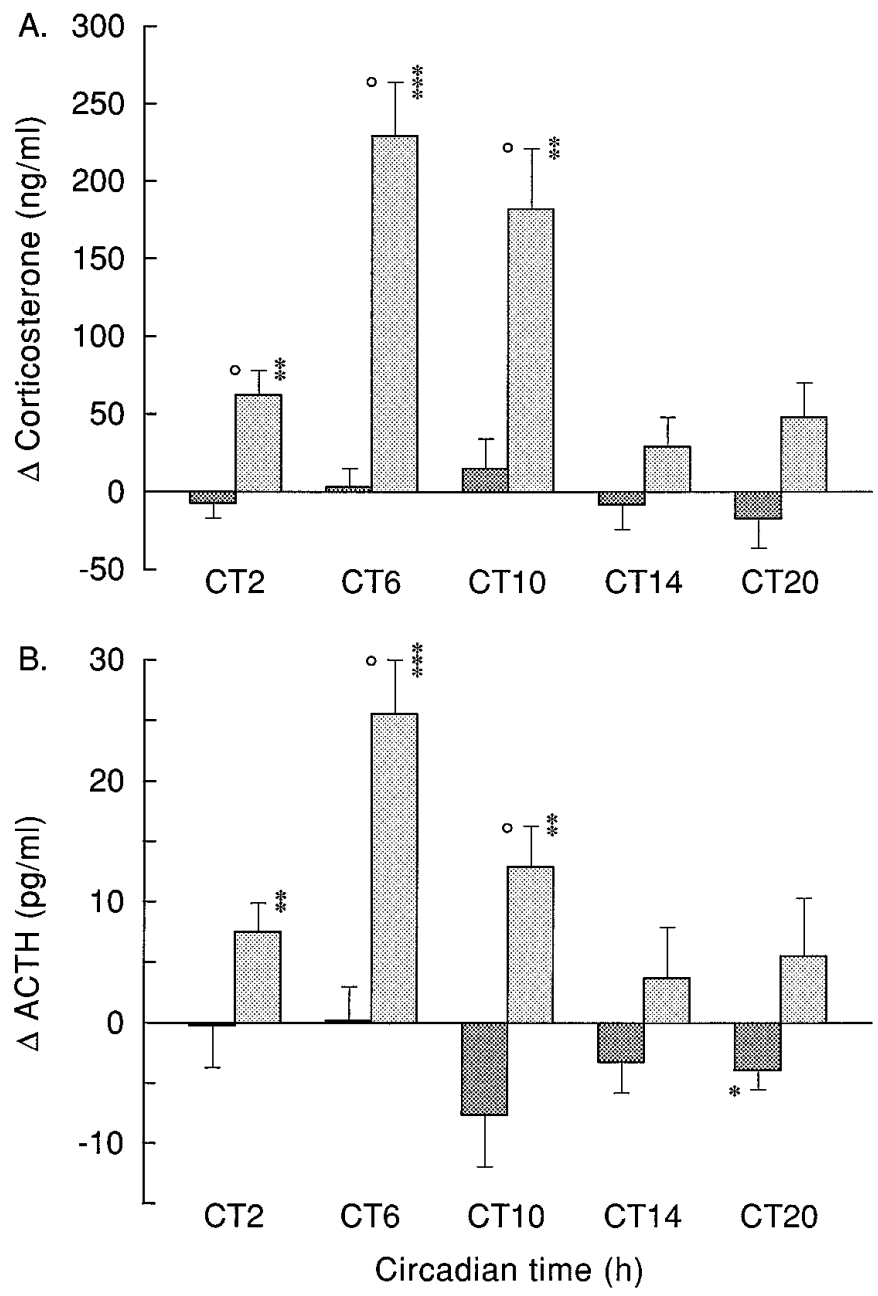

Figure 5. Plasma corticosterone $(A)$ and ACTH $(B)$ responses at different CT times, 30 min after onset of Ringer's (dark bars) or VP antagonist (light bars) administration. For absolute corticosterone and ACTH values at $t=-1$, see Table 2. Circle, Ringer's versus VP antagonist, $p<0.05$. Asterisks, $t=30$ versus $t=-1$; ${ }^{*}, * *$, and $* * *$ indicate $p<0.05, p<0.01$, and $p<0.001$, respectively.

abates, and the circulating levels of corticosterone consequently slowly decrease as a result of catabolism in the peripheral circulation. The fact that the endogenous, diurnal peak in plasma corticosterone is only half as high as the $\mathrm{V}_{1}$ antagonist-induced alterations at CT6 and CT10 is attributable to the fact that, during the diurnal peak, the inhibitory effect of VP diminishes but is not yet completely absent. The normal basal corticosterone peak thus is still partly inhibited by VP.

The control of the circadian rhythm in corticosterone release might be effected either via changes in its central drive (i.e., secretion of $\mathrm{CRH}$ and $\mathrm{ACTH}$ ) or by changes in the adrenal sensitivity to ACTH (Wilkinson et al., 1979; Kaneko et al., 1981; Charlton, 1990). To investigate further the neural mechanisms underlying the circadian control of corticosterone release, we also measured plasma ACTH levels. Contrary to the corticosterone data, ACTH levels showed no diurnal variation during the different Ringer's infusions $(p>0.5)$, although variability during the CT10 experiment was considerably higher than at any other time of the day $(16.8 \pm 2.8$ vs $6.8 \pm 1.9,7.6 \pm 2.3,10.6 \pm 1.1$, and $11.0 \pm 2.4 \mathrm{pg} / \mathrm{ml})$. A number of previous studies have reported diurnal variations in plasma ACTH levels (Graf et al., 1988;

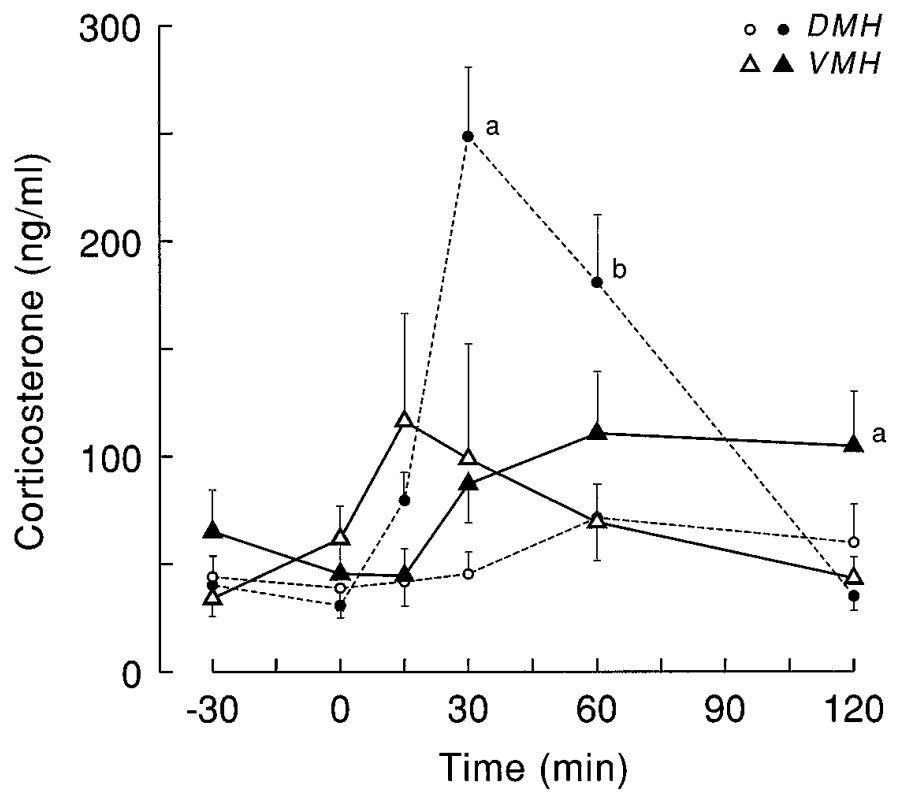

Figure 6. Plasma corticosterone values (mean \pm SEM) as a result of Ringer's (open symbols) and VP antagonist (solid symbols) administration into either the DMH (circles) or VMH (triangles). $a$, Significantly different from all three other groups; $b$, significantly different from Ringer's-infused groups.

Carnes et al., 1989; Bagdy et al., 1991; Kwak et al., 1992; Ixart et al., 1993), but quite a few others failed to detect significant diurnal variations (Wilkinson et al., 1979; Akana et al., 1986; Carnes et al., 1986; Cascio et al., 1987; Kwak et al., 1993; Suemaru et al., 1995). Important factors that may contribute to the difficulty of finding a circadian ACTH rhythm are the low amplitude of the rhythm, the episodic secretion of ACTH, the sampling protocol used (Carnes et al., 1986; Turek and Van Cauter, 1988; Carnes et al., 1989), and the assay variability (e.g., CT times in different assays).

The observation that the vasopressin $V_{1}$ antagonist caused a significant increase of plasma ACTH levels during every daytime administration, but not during the dark period (Figs. 4, 5, Table 3 ), suggests that VP from the SCN inhibits corticosterone release during the daytime via an inhibitory effect on the release of ACTH. However, contrary to the increased release of corticosterone, the ACTH responses were not very pronounced. Indeed, during the stress paradigm the lower corticosterone excursions were accompanied by higher ACTH levels (Fig. 7), which is why we think that the main control by the SCN does, perhaps, not occur via a direct effect on the release of $\mathrm{ACTH}$, but via changes in the adrenal sensitivity to ACTH. The scatter plot in Figure 8 illustrates this point very clearly. Stress-induced increases of plasma corticosterone are accompanied by increased levels of plasma ACTH. On the other hand, the VP antagonist-induced increments in plasma corticosterone, and possibly also the circadian peak, seem to be completely independent of changes in $\mathrm{ACTH}$ release. A similar trend for an ACTH-independent increase of corticosterone levels during the circadian peak was previously noted by Dallman et al. (1987). Jasper and Engeland (1994) showed that denervation of the adrenal gland by removal of its sympathetic innervation resulted in increased secretory activity of the adrenal cortex during the daytime, thus supporting our suggestion for an important daytime inhibition of corticosterone release via the neural input to the adrenal gland. Recently, Dijkstra et al. (1996) also showed that the sympathetic innervation 

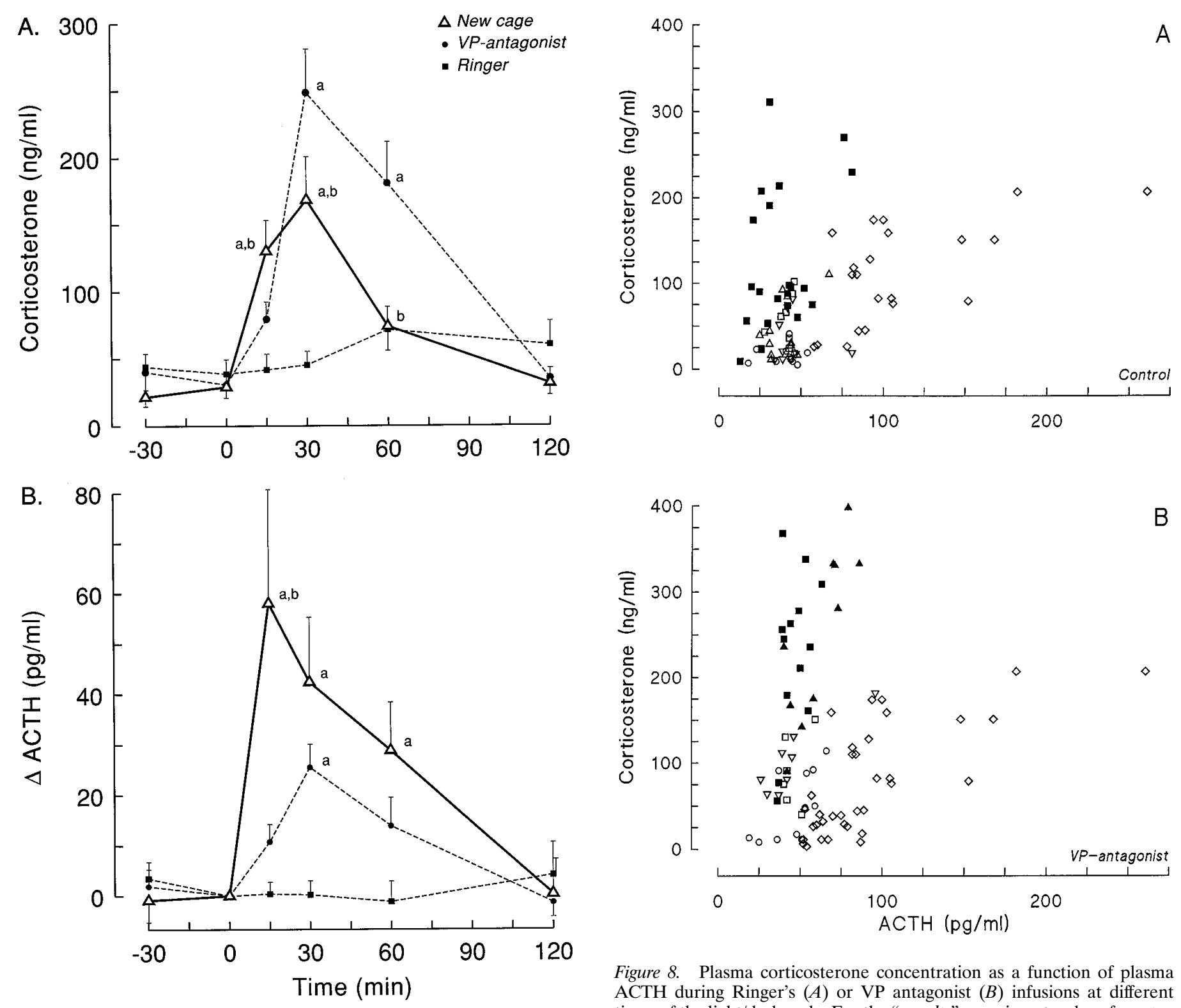

Figure 7. Changes in circulating levels of plasma corticosterone $(A)$ and ACTH $(B)$ induced by microdialysis-mediated administration of VP antagonist in the PVN/DMH area at CT6 (Ringer's, $\mathbf{\square}, n=11$; VP antagonist, $\bullet, n=10$ ) or exposure to a new environment (New cage, $\triangle, n=7$ ). Letters indicate significant differences compared with Ringer's $(a)$ and VP antagonist $(b)$ according to Student-Newman-Keuls $(p<0.05)$.

of the adrenal gland contributes to the diurnal variation in resting plasma corticosterone levels. However, evidence also was provided that this is not attributable to a change in the adrenal responsiveness to ACTH. Therefore, the main effect of VP released from SCN terminals in the PVN/DMH area might be to decrease splanchnic neural activity by affecting PVN/DMH neurons with descending projections to brainstem and spinal cord. Indeed, Nagai et al. (1995) recently showed a strong inhibitory effect of centrally (i.e., intracerebroventricular) administered VP on sympathetic nerve activity. Other data, however, support a stimulation (Holt and York, 1989). We are currently pursuing this line of research by investigating the effect of VP antagonist administration on corticosterone levels after central denervation of the adrenal.

Figure 8. Plasma corticosterone concentration as a function of plasma ACTH during Ringer's $(A)$ or VP antagonist $(B)$ infusions at different times of the light/dark cycle. For the "novelty" experiment, values from $t=$ 15,30 , and $60 \mathrm{~min}$ samples were used. From the VP antagonist infusions, only the $t=30$ values are displayed. Data from the Ringer's infusions are derived also from the $t=30$ samples, except the infusion at CT10, from which data from the $t=60$ samples are also displayed. CT2 $=0$; CT6 $=$ $\triangle(A)$ or $\mathbf{\Delta}(B) ; \mathrm{CT} 10=\mathbf{\square}$; CT14 $=\square ;$ CT22 $=\nabla ;$ novelty $=\diamond$.

Contrary to stress-induced corticosterone elevations, the magnitudes of ACTH responses to stress are largest in the early light period and smallest during the period of light-dark transition (Bradbury et al., 1991). Buijs et al. (1993a) noted previously that the dichotomous effect of stress on corticosterone and ACTH excursions indicates the existence of separate hypothalamic control systems for corticosterone and ACTH release, both influenced by the SCN. As discussed above, the inhibitory (i.e., VPergic) control of the SCN may be exerted via the sympathetic innervation of the adrenal gland. Based on the existence of separate control systems for ACTH and corticosterone release, it is tempting to speculate that the facilitatory influence of the SCN may be the result of stimulation of the synthesis and release of CRH, and subsequently of ACTH. In this respect, it is remarkable that both GRP and VIP (i.e., two 


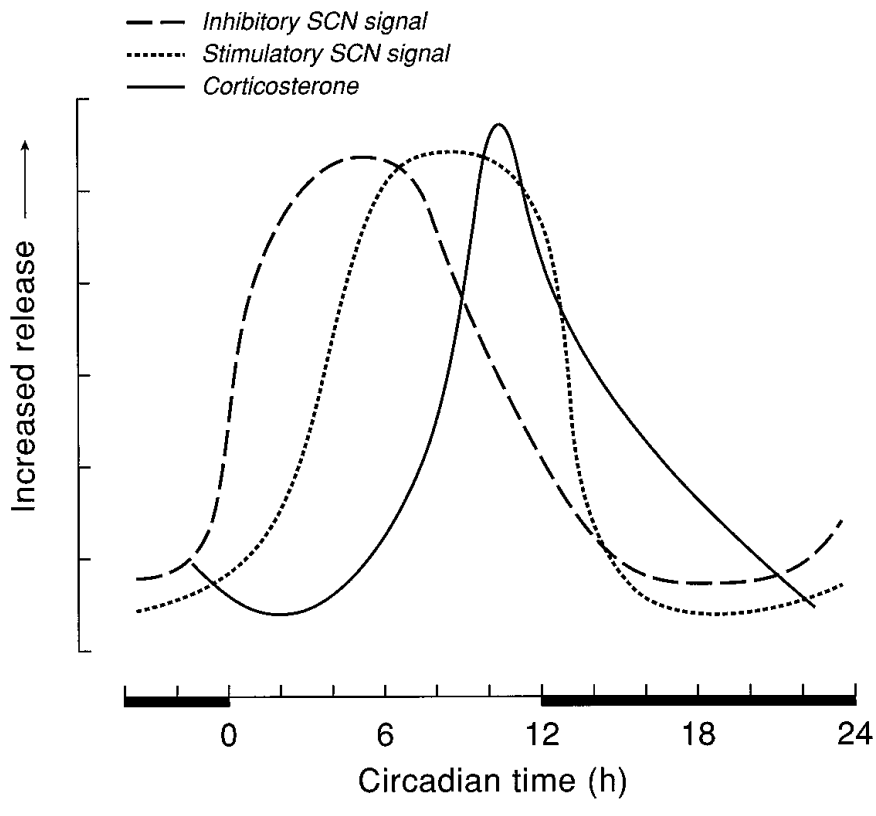

Figure 9. Schematic presentation of the diurnal release pattern of SCN transmitters involved in the circadian control of corticosterone release. Vasopressin (i.e., inhibitory SCN signal) and corticosterone data are redrawn from previously published data (Kalsbeek et al., 1995, 1996), whereas the release pattern of the SCN transmitter stimulating the HPA axis is extrapolated from the data presented in Figure 5.

peptidergic transmitters contained in SCN neurons) exhibit $\mathrm{ACTH}$ and corticosterone release stimulating properties (Gunion et al., 1989; Olsen et al., 1992; Alexander and Sander, 1994). The early onset of the stimulatory SCN input (i.e., between CT2 and CT6), as revealed by our timed VP antagonist infusions, would agree with the often-reported phaseadvanced rhythms of $\mathrm{CRH}$ and $\mathrm{ACTH}$ compared with that of corticosterone (Szafarczyk et al., 1980; Graf et al., 1988; Carnes et al., 1989; Owens et al., 1990; Kwak et al., 1992; Cai and Wise, 1996) and the elevated daytime levels of GRP mRNA in the SCN (Zoeller et al., 1992; Inouye et al., 1993; Inouye and Shibata, 1994). Because VP-, VIP-, and GRP-containing SCN fibers display clearly separated innervation patterns of the PVN/DMH subdivisions (Buijs et al., 1993b; Kalsbeek et al., 1993), a differentiated control of ACTH and corticosterone release by SCN efferences is certainly possible. However, as yet no conclusive anatomical data are available to back up the dual control pattern of ACTH and corticosterone release as proposed in the foregoing.

Our control experiment (Fig. 6) shows that diffusion of VP antagonist away from the infusion site is limited, and confirms that the DMH is a critical site of action for VP. The evidence for the SCN being the major source of this rhythmic VPergic input to the $\mathrm{DMH}$ is threefold. (1) Anatomically, the only extrinsic VPcontaining input to the DMH known is the SCN, an input that completely disappears after SCN lesions (Hoorneman and Buijs, 1982; Kalsbeek et al., 1993). (2) In SCN-lesioned animals, VP antagonist infusions are noneffective (Kalsbeek et al., 1992). (3) VP release from SCN, and not PVN or SON terminals, shows a daily rhythm (Kalsbeek et al., 1995). The only other possible source of VP fibers in the DMH is an intrinsic one, i.e., the magno- and/or parvocellular VP-containing neurons. Numerous reports, however, have shown that VP from parvocellular and perhaps magnocellular PVN neurons has an excitatory instead of an inhibitory influence on HPA axis activity (Gillies et al., 1982; Rivier and Vale, 1983; De Goeij et al., 1992; Bernardini et al., 1994). Therefore, we suggest that in the control of corticosterone secretion, the CNS uses VP in two apparently opposite ways. VP synthesized in SCN neurons and released in the PVN/DMH area as a neurotransmitter serves to inhibit corticosterone release, whereas the (parvocellular) neurons in the PVN that produce VP act to promote the release of ACTH via its release in the median eminence.

In conclusion, the present results show that two rhythmic inputs from the SCN explain the well known daily pattern of basal corticosterone release. In addition to this endogenous circadian factor, environmental factors such as light, food, development, and stress also may affect the daily activity of the HPA axis profoundly. Light effects are mainly exerted via the SCN, but the other factors probably use different pathways, such as the noradrenergic input from the brainstem and the neuropeptide Y-containing input from the arcuate nucleus (De Kloet et al., 1988; Dallman et al., 1993; Ericsson et al., 1994; Hanson and Dallman, 1995; Shintani et al., 1995).

\section{REFERENCES}

Abe K, Kroning J, Greer MA, Critchlow V (1979) Effects of destruction of the suprachiasmatic nuclei on the circadian rhythms in plasma corticosterone, body temperature, feeding and plasma thyrotropin. Neuroendocrinology 29:119-131.

Akana SF, Cascio CS, Du J-Z, Levin N, Dallman MF (1986) Reset of feedback in the adrenocortical system: an apparent shift in sensitivity of adrenocorticotropin to inhibition by corticosterone between morning and evening. Endocrinology 119:2325-2332.

Alexander LD, Sander LD (1994) Vasoactive intestinal peptide stimulates ACTH and corticosterone release after injection into the PVN. Regul Pept 51:221-227.

Bagdy G, Chrousos GP, Calogero AE (1991) Circadian patterns of plasma immunoreactive corticotropin, beta-endorphin, corticosterone and prolactin after immunoneutralization of corticotropin-releasing hormone. Neuroendocrinology 53:573-578.

Bernardini R, Chiarenza A, Kamilaris TC, Renaud N, Lempereur L, Demitrack M, Gold PW, Chrousos GP (1994) In vivo and in vitro effects of arginine-vasopressin receptor antagonists on the hypothalamic-pituitary-adrenal axis in the rat. Neuroendocrinology 60:503-508.

Bos NPA, Mirmiran M (1990) Circadian rhythms in spontaneous neuronal discharges of the cultured suprachiasmatic nucleus. Brain Res 511:158-162.

Bradbury MJ, Cascio CS, Scribner KA, Dallman MF (1991) Stressinduced adrenocorticotropin secretion: diurnal responses and decreases during stress in the evening are not dependent on corticosterone. Endocrinology 128:680-688.

Buijs RM, Kalsbeek A, Van Der Woude TP, Van Heerikhuize JJ, Shinn S (1993a) Suprachiasmatic nucleus lesion increases corticosterone secretion. Am J Physiol 264:R1186-R1192.

Buijs RM, Markman M, Nunes-Cardoso B, Hou Y-X, Shinn S (1993b) Projections of the suprachiasmatic nucleus to stress-related areas in the rat hypothalamus: a light and electron microscopic study. J Comp Neurol 335:42-54.

Cai AH, Wise PM (1996) Age-related changes in the diurnal rhythm of $\mathrm{CRH}$ gene expression in the paraventricular nuclei. Am J Physiol 33:E238-E243.

Carnes M, Brownfield MS, Kalin NH, Lent S, Barksdale CM (1986) Episodic secretion of ACTH in rats. Peptides 7:219-223.

Carnes M, Kalin NH, Lent SJ, Barksdale CM, Brownfield MS (1988) Pulsatile ACTH secretion: variation with time of day and relationship to cortisol. Peptides 9:325-331.

Carnes M, Lent S, Hazel D (1989) Plasma adrenocorticotropic hormone in the rat demonstrates three different rhythms within $24 \mathrm{hr}$. Neuroendocrinology 50:17-25.

Carnes M, Lent SJ, Goodman B, Mueller C, Saydoff J, Erisman S (1990) Effects of immunoneutralization of corticotropin-releasing hormone on ultradian rhythms of plasma adrenocorticotropin. Endocrinology 126:1904-1913. 
Cascio CS, Shinsako J, Dallman MF (1987) The suprachiasmatic nuclei stimulate evening ACTH secretion in the rat. Brain Res 423:173-178.

Challet E, Le Maho Y, Robin JP, Malan A, Cherel Y (1995) Involvement of corticosterone in the fasting-induced rise in protein utilization and locomotor activity. Pharmacol Biochem Behav 50:405-412.

Charlton BG (1990) Adrenal cortical innervation and glucocorticoid secretion. J Endocrinol 126:5-8.

Dallman MF, Akana SF, Cascio CS, Darlington DN, Jacobson L, Levin N (1987) Regulation of ACTH secretion: variations on a theme of B. Recent Prog Horm Res 43:113-173.

Dallman MF, Akana SF, Scribner KA, Bradbury MJ, Walker CD, Strack AM, Cascio CS (1992) Stress, feedback and facilitation in the hypothalamo-pituitary-adrenal axis. J Neuroendocrinol 4:517-526.

Dallman MF, Strack AM, Akana SF, Bradbury MJ, Hanson ES, Scribner KA, Smith M (1993) Feast and famine-critical role of glucocorticoids with insulin in daily energy flow. Front Neuroendocrinol 14:303-347.

De Goeij DCE, Jezova D, Tilders FJH (1992) Repeated stress enhances vasopressin synthesis in corticotropin releasing factor neurons in the paraventricular nucleus. Brain Res 577:165-168.

De Kloet ER, Rosenfeld P, Van Eekelen JAM, Sutanto W, Levine S (1988) Stress, glucocorticoids and development. In: Progress in brain research. Biochemical basis of functional neuroteratology (Boer GJ, Feenstra MGP, Mirmiran M, Swaab DF, Van Haaren F, eds), pp 101-120. Amsterdam: Elsevier.

Devenport L, Doughty D, Heiberger B, Burton D, Brown R, Stith R (1993) Exercise endurance in rats-roles of type-I and type-II corticosteroid receptors. Physiol Behav 53:1171-1175.

Dijkstra I, Binnekade R, Tilders FJH (1996) Diurnal variation in resting levels of corticosterone is not mediated by variation in adrenal responsiveness to adrenocorticotropin but involves splanchnic nerve integrity. Endocrinology 137:540-547.

Drijfhout WJ, Kemper RHA, Meerlo P, Koolhaas JM, Grol CJ, Westerink BHC (1995) A telemetry study on the chronic effects of microdialysis probe implantation on the activity pattern and temperature rhythm of the rat. J Neurosci Methods 61:191-196.

Ericsson A, Kovacs KJ, Sawchenko PE (1994) A functional anatomical analysis of central pathways subserving the effects of interleukin-1 on stress-related neuroendocrine neurons. J Neurosci 14:897-913.

Fischman AJ, Kastin AJ, Graf MV, Moldow RL (1988) Constant light and dark affect the circadian rhythm of the hypothalamic-pituitaryadrenal axis. Neuroendocrinology 47:309-316.

Gillette MU, Reppert SM (1987) The hypothalamic suprachiasmatic nuclei: circadian patterns of vasopressin secretion and neuronal activity in vitro. Brain Res Bull 19:135-139.

Gillies GE, Linton EA, Lowry PJ (1982) Corticotropin releasing activity of the new CRF is potentiated several times by vasopressin. Nature 299:355-357.

Graf M, Fishman AJ, Kastin AJ, Moldow RL (1988) Circadian variation in response to CRF-41 and AVP. Am J Physiol 255:E265-E271.

Guillemin R, Dear WE, Liebelt RA (1959) Nyctohemeral variations in plasma free corticosteroid levels in the rat. Proc Soc Exp Biol Med 101:394-395.

Gunion MW, Tache Y, Rosenthal MJ, Miller S, Butler B, Zib B (1989) Bombesin microinfusion into the rat hypothalamic paraventricular nucleus increases blood glucose, free fatty acids and corticosterone. Brain Res 478:47-58.

Hamelink CR, Currie PJ, Chambers JW, Castonguay TW, Coscina DV (1994) Corticosterone-responsive and -unresponsive metabolic characteristics of adrenalectomized rats. Am J Physiol 267:R799-R804.

Hanson ES, Dallman MF (1995) Neuropeptide Y (NPY) may integrate responses of hypothalamic feeding systems and the hypothalamopituitary-adrenal axis. J Neuroendocrinol 7:273-279.

Holt SJ, York DA (1989) The effects of adrenalectomy, corticotropin releasing factor and vasopressin on the sympathetic firing rate of nerves to interscapular brown adipose tissue in the zucker rat. Physiol Behav 45:1123-1129.

Hoorneman EMD, Buijs RM (1982) Vasopressin fiber pathways in the rat brain following suprachiasmatic nucleus lesioning. Brain Res 243:235-241.

Inouye SIT, Kawamura H (1979) Persistence of circadian rhythmicity in a mammalian hypothalamic "island" containing the suprachiasmatic nucleus. Proc Natl Acad Sci USA 76:5962-5966.

Inouye SIT, Shibata S (1994) Neurochemical organization of circadian rhythm in the suprachiasmatic nucleus. Neurosci Res 20:109-130.
Inouye SIT, Shinohara K, Tominaga K, Takeuchi J, Nagasaki H, Isobe Y, Fukuhara C, Otori Y, Yang J, Cagampang FRA, Yamazaki S, Tokumasu A (1993) Circadian rhythms in peptides and their precursor messenger RNAs in the suprachiasmatic nucleus. In: New functional aspects of the suprachiasmatic nucleus of the hypothalamus (Nakagawa H, Oomura Y, Nagai K, eds), pp 219-233. London: Libbey.

Irvine CHG, Alexander SL (1994) Factors affecting the circadian rhythm in plasma cortisol concentrations in the horse. Domest Anim Endocrinol 11:227-238.

Ixart G, Siaud P, Barbanel G, Mekaouche M, Givalois L, Assenmacher I (1993) Circadian variations in the amplitude of corticotropin-releasing hormone 41 (Crh41) episodic release measured in vivo in male ratscorrelations with diurnal fluctuations in hypothalamic and median eminence Crh41 contents. J Biol Rhythms 8:297-309.

Jasper MS, Engeland WC (1994) Splanchnic neural activity modulates ultradian and circadian rhythms in adrenocortical secretion in awake rats. Neuroendocrinology 59:97-109.

Kalsbeek A, Buijs RM (1996) Rhythms of inhibitory and excitatory output from the circadian timing system as revealed by in vivo microdialysis. In: Hypothalamic integration of circadian rhythms, progress in brain research, Vol 95 (Buijs RM, Kalsbeek A, Mirmiran M, Pennartz CMA, Romijn HJ, eds), pp 271-291. Amsterdam: Elsevier.

Kalsbeek A, Buijs RM, Van Heerikhuize JJ, Arts M, Van Der Woude TP (1992) Vasopressin-containing neurons of the suprachiasmatic nuclei inhibit corticosterone release. Brain Res 580:62-67.

Kalsbeek A, Teclemariam-Mesbah R, Pévet P (1993) Efferent projections of the suprachiasmatic nucleus in the golden hamster (Mesocricetus auratus). J Comp Neurol 332:293-314.

Kalsbeek A, Buijs RM, Engelmann M, Wotjak CT, Landgraf R (1995) In vivo measurement of a diurnal variation in vasopressin release in the rat suprachiasmatic nucleus. Brain Res 682:75-82.

Kalsbeek A, Drijfhout WJ, Westerink BHC, Van Heerikhuize JJ, Van Der Woude T, Van Der Vliet J, Buijs RM (1996) GABA receptors in the region of the dorsomedial hypothalamus of rats are implicated in the control of melatonin. Neuroendocrinology 63:69-78.

Kalsbeek A, Van Der Vliet J, Buijs RM (1996) Decrease of endogenous vasopressin release necessary for expression of the circadian rise in plasma corticosterone: a reverse microdialysis study. J Neuroendocrinol 8:299-307.

Kaneko M, Kaneko K, Shinsako J, Dallman MF (1981) Adrenal sensitivity to adrenocorticotropin varies diurnally. Endocrinology 109:70-75.

Klemcke HG, Nienaber JA, Hahn GL (1989) Plasma adrenocorticotropic hormone and cortisol in pigs: effects of time of day on basal and stressor-altered concentrations. Proc Soc Exp Biol Med 190:42-53.

Kwak SP, Young EA, Morano I, Watson SJ, Akil H (1992) Diurnal corticotropin-releasing hormone messenger RNA variation in the hypothalamus exhibits a rhythm distinct from that of plasma corticosterone. Neuroendocrinology 55:74-83.

Kwak SP, Morano MI, Young EA, Watson SJ, Akil H (1993) Diurnal CRH messenger RNA rhythm in the hypothalamus. Decreased expression in the evening is not dependent on endogenous glucocorticoids. Neuroendocrinology 57:96-105.

Lefcourt AM, Bitman J, Kahl S, Wood DL (1993) Circadian and ultradian rhythms of peripheral cortisol concentrations in lactating dairy cows. J Dairy Sci 76:2607-2612.

Lincoln GA, Almeida OFX, Klandorf H, Cunningham RA (1982) Hourly fluctuations in the blood levels of melatonin, prolactin, luteinizing hormone, follicle-stimulating hormone, testosterone, triiodothyronine, thyroxine and cortisol in rams under artificial photoperiods, and the effects of cranial sympathectomy. $\mathrm{J}$ Endocrinol 92:237-250.

Linkowski P, Van Onderbergen A, Kerkhofs M, Bosson D, Mendlewicz J, Van Cauter E (1993) Twin study of the 24-h cortisol profile- evidence for genetic control of the human circadian clock. Am J Physiol 264:E173-E181.

Manning M, Sawyer WH (1984) Design and uses of selective agonistic and antagonistic analogs of the neuropeptides oxytocin and vasopressin. Trends Neurosci 7:6-9.

Manning M, Stoev S, Chan WY, Sawyer WH (1993) Receptor-specific antagonists of vasopressin and oxytocin. Ann NY Acad Sci 689:219-232.

McCarthy JL, Corley RC, Zarrow MX (1960) Diurnal rhythm in plasma corticosterone and lack of diurnal rhythm in plasma compound F-like material in the rat. Proc Soc Exp Biol Med 104:787-789. 
Moore RY, Eichler VB (1972) Loss of a circadian adrenal corticosterone rhythm following suprachiasmatic lesions in the rat. Brain Res 42:201-206.

Munck A, Guyre PM, Holbrook NJ (1984) Physiological functions of glucocorticoids in stress and their relation to pharmacological actions. Endocr Rev 5:25-44.

Nagai N, Nagai K, Takezawa K, Chun SJ, Nakagawa H (1995) Suppressive effect of vasopressin on the hyperglycemic response to intracranial injection of 2-deoxy-D-glucose. Neurosci Lett 190:187-190.

Olsen L, Knigge U, Warberg J (1992) Gastrin-releasing peptide stimulation of corticotropin secretion in male rats. Endocrinology 130:2710-2716.

Owens MJ, Bartolome J, Schanberg SM, Nemeroff CB (1990) Corticotropin-releasing factor concentrations exhibit an apparent diurnal rhythm in hypothalamic and extrahypothalamic brain regions: differential sensitivity to corticosterone. Neuroendocrinology 52:626-631.

Perlow MJ, Reppert SM, Boyart RM, Klein DC (1981) Daily rhythms in cortisol and melatonin in primate cerebrospinal fluid. Effects of constant light and dark. Neuroendocrinology 32:193-196.

Reppert SM, Artman HG, Swaminathan S, Fisher DA (1981) Vasopressin exhibits a rhythmic daily pattern in cerebrospinal fluid but not in blood. Science 213:1256-1257.

Rivier C, Vale W (1983) Modulation of stress-induced ACTH release by corticotropin-releasing factor, catecholamines and vasopressin. Nature 305:325-327.

Shintani F, Nakaki T, Kanba S, Sato K, Yagi G, Shiozawa M, Aiso S, Kato $\mathrm{R}$, Asai M (1995) Involvement of interleukin-1 in immobilization stress-induced increase in plasma adrenocorticotropic hormone and in release of hypothalamic monoamines in the rat. $\mathbf{J}$ Neurosci 15:1961-1970.

Steffens AB (1969) A method for frequent sampling blood and continuous infusion of fluids in the rat without disturbing the animal. Physiol Behav 4:833-836.
Suemaru S, Darlington DN, Akana SF, Cascio CS, Dallman MF (1995) Ventromedial hypothalamic lesions inhibit corticosteroid feedback regulation of basal ACTH during the trough of the circadian rhythm. Neuroendocrinology 61:453-463.

Szafarczyk A, Ixart G, Malaval F, Nouguier-Soule J, Assenmacher I (1979) Effects of lesions of the suprachiasmatic nuclei and of p-chlorophenylalanine on the circadian rhythms of adrenocorticotrophic hormone and corticosterone in the plasma, and on locomotor activity of rats. J Endocrinol 83:1-16.

Szafarczyk A, Hery M, Laplante E, Ixart G, Assenmacher I, Kordon C (1980) Temporal relationships between the circadian rhythmicity in plasma levels of pituitary hormones and in hypothalamic concentrations of releasing factors. Neuroendocrinology 30:369-376.

Takahashi K, Inoue K, Takahashi Y (1977) Parallel shift in circadian rhythms of adrenocortical activity and food intake in blinded and intact rats exposed to continuous illumination. Endocrinology 100:1097-1107.

Tempel DL, Leibowitz SF (1994) Adrenal steroid receptors: interactions with brain neuropeptide systems in relation to nutrient intake and metabolism. J Neuroendocrinol 6:479-501.

Turek FW, Van Cauter E (1988) Rhythms in reproduction. In: The physiology of reproduction (Knobil E, Neill J, eds), pp 1789-1830. London: Raven.

Van Cauter E (1990) Diurnal and ultradian rhythms in human endocrine function: a mini review. Horm Metab Res 34:45-53.

Wilkinson CW, Shinsako J, Dallman MF (1979) Daily rhythms in adrenal responsiveness to adrenocorticotropin are determined primarily by the time of feeding in the rat. Endocrinology 104:350-359.

Zoeller RT, Broyles B, Earley J, Anderson ER, Albers HE (1992) Cellular levels of messenger ribonucleic acids encoding vasoactive intestinal peptide and gastrin-releasing peptide in neurons of the suprachiasmatic nucleus exhibit distinct 24-hour rhythms. J Neuroendocrinol 4:119-124. 